\title{
DIMENSÕES SOCIOCULTURAIS DO BOXE: PERCEPÇÃO E TRAJETÓRIA DE MULHERES ATLETAS
}

\author{
SOCIO-CULTURAL DIMENSIONS OF BOXING: WOMEN ATHLETES' PERCEPTION \\ AND CAREER
}
DIMENSIONES SOCIO-CULTURALES DE BOXEO: PERCEPCION Y CARRERA DE ATLETAS MUJERES Berta Leni Costa Cardoso*, Tânia Mara Vieira Sampaio**, Doiara Silva dos
Santos $^{\star \star *}$

Palavras-chave

Mulheres.

Atletas.

Boxe.

Keywords

Women.

Athletes.

Boxing.

Palabras clave

Mujeres.

Atletas.

Boxeo.
Resumo: 0 objetivo deste trabalho foi analisar a trajetória e percepcão de atletas do boxe feminino sobre o esporte escolhido como profissão quanto a dimensões socioculturais. Para tanto, foram realizadas entrevistas semiestruturadas com sete boxeadoras profissionais do Brasil. Metodologicamente, combinou-se o programa ALCESTE (Analyse Lexicale par Contexte d'un Ensemble de Segments de Texte) e a Análise de Conteúdo. A partir da análise em classes temáticas, discutiu-se o relato de que o boxe feminino capitaliza poucos incentivos financeiros e pouca divulgação. Constatou-se também que, ao longo de sua trajetória, as entrevistadas se depararam com dificuldades quanto ao apoio da família e preconceitos.

Abstract: This study aimed at examining the history and perception of female boxing athletes about their sporting careers regarding sociocultural dimensions. Semi-structured interviews were conducted with seven Brazilian professional female boxers. Methodologically, the study combined the software Analyse Lexicale par Contexte d'un Ensemble de Segments de Texte (ALCESTE) and Content Analysis. After thematic class-based analysis, we discussed the view that female boxing capitalizes few financial incentives and little publicity. We also found that, throughout their history, respondents have faced difficulties in terms of family support and prejudices.

Resumen: El objetivo de este trabajo fue analizar la trayectoria y percepción de atletas del boxeo femenino sobre el deporte escogido como profesión en cuanto a sus dimensiones socioculturales. Para ello, se realizaron entrevistas semiestructuradas con siete boxeadoras profesionales brasileñas. Metodológicamente, se combina el software ALCESTE (Analyse Lexicale par Contexte d'un Ensemble de Segments de Texte) y el Análisis de Contenido. A partir del análisis en clases temáticas, se discutió el relato de que el boxeo femenino capitaliza pocos incentivos financieros y tiene poca divulgación. También se constató que, a lo largo de su trayectoria, las entrevistadas se han enfrentado a dificultades en lo que se refiere al apoyo familiar y a los prejuicios.
*Universidade do Estado da Bahia (UNEB). Salvador, BA, Brasil. E-mail: bertacostacardoso@yahoo.com.br

** Universidade Católica de Brasília. Brasília, DF, Brasil.

E-mail: : tsampaio@ucb.br

*** Western University. London, Ontário, Canadá. E-mail: dsilvado@uwo.ca

Recebido em: 11-04-2014 Aprovado em: 21-01-2015 (c) (i) () Licence 


\section{INTRODUÇÃO}

Embora as crescentes transformações sociais estejam modificando antigas concepções no que se refere à questão de gênero, observa-se que persiste a existência de preconceitos e discriminações em relação à participação feminina em várias esferas da sociedade, incluindo o esporte. Tais preconceitos e discriminações no meio esportivo se tornam ainda mais evidentes quando mulheres engajam-se em modalidades hegemonicamente masculinas, tal como o boxe (OLIVEIRA, CHEREM, TUBINO, 2008).

O binômio feminino-masculino tem orientado as competições esportivas em geral e também as modalidades olímpicas desde 0 início da sistematização do esporte moderno. Há modalidades olímpicas disputadas apenas pelos homens (tal como o decatlo) e há aquelas de participação exclusivamente feminina, como, por exemplo, a ginástica rítmica e o nado sincronizado.

Historicamente, a participação feminina no meio esportivo é menor que a dos homens, tanto exercendo a função de atletas, como ocupando cargos de técnicas, treinadoras ou gestoras. Até mesmo em equipes ou em competições femininas o que se vê é a hegemonia masculina na maioria dos cargos que envolvem autoridade (GOMES, 2008).

Ainda hoje se percebe o predomínio masculino no que diz respeito à participação nos Jogos Olímpicos modernos. $O$ evento em si foi planejado e idealizado pelo barão francês Pierre de Coubertin, que, pessoalmente, desencorajava a prática de atividades esportivas competitivas para mulheres por acreditar no esporte como um meio de celebrar e promover virtudes masculinas (ROMARIZ; DEVIDE; VOTRE, 2007).

Apesar do posicionamento contrário do idealizador dos Jogos Olímpicos modernos, algumas modalidades esportivas que contemplam a participação feminina estiveram presentes no programa de competições olímpicas desde o seu início, como a ginástica (embora, em suas primeiras edições, em caráter de demonstração). Isso ocorreu, a princípio, pelo fato de as federações internacionais e, posteriormente, os comitês organizadores das cidades-sede, serem responsáveis pela escolha do programa de eventos dos Jogos Olímpicos e, com isso, utilizarem sua relativa autonomia para a inclusão das mulheres apenas em algumas modalidades (MacALOON, 1984).

É preciso ressaltar que, ao longo da história, os critérios de elegibilidade para a inclusão de modalidades esportivas no programa olímpico se tornaram cada vez mais flexíveis e mais atentos à questão de gênero, acompanhando mudanças da sociedade moderna em geral, com a conquista de vários direitos para as mulheres ao longo do século XX. Gradualmente, esse processo levou ao quadro atual, em que as mulheres têm representação/participação em todas as modalidades olímpicas (COMITÊ OLÍMPICO INTERNACIONAL, 2013).

O boxe tornou-se modalidade olímpica para homens a partir de 1904. Mais de cem anos depois, o Conselho Executivo do Comitê Olímpico Internacional cogitou incluir o boxe feminino no programa de eventos da competição em 2008. Porém, somente em reunião no dia 13 de agosto de 2009 tal decisão foi encaminhada para a inclusão da modalidade feminina, em três categorias, nos Jogos Olímpicos de 2012 (COI..., 2009). Vale mencionar que três atletas

1 Houve apenas uma interrupção quanto à presença desta modalidade nos Jogos Olímpicos. Isto ocorreu em Estocolmo em 1912, porque o país sede bania a prática do boxe por lei, considerando a modalidade uma prática violenta e rudimentar. Ver: < http://www. 
brasileiras participaram da estreia do boxe feminino nos Jogos Olímpicos de Londres, resultando na conquista de uma medalha de bronze. ${ }^{2}$

Verifica-se na literatura acadêmica a existência de poucas publicações em português sobre o boxe. Algumas obras apresentam informes sobre regras, normas, ensino de técnicas, compilação de resultados e pequenos relatos sobre histórias de boxeadores. Especificamente quanto aos estudos sobre a participação das mulheres no boxe, estes são raros no Brasil e, em sua maioria, enfatizam a existência do preconceito nesse esporte (FERRETTI; KNIJNIK, 2007).

A produção acadêmica internacional, por sua vez, tem identificado que o boxe feminino foi negligenciado nos estudos sobre a modalidade até a década de 1990 na Europa e nos Estados Unidos, tal como aponta a pesquisa de Halbert (1997). Somente a partir dos anos $2000 \mathrm{a}$ literatura internacional sobre o boxe feminino cresceu, conforme se verifica no estudo de Boyle, Millington e Vertinsky (2006).

Identificar tal lacuna motivou a produção desta pesquisa, sobretudo, numa perspectiva que não enfatiza elementos técnicos, dados antropométricos, regras e/ou informes de resultados obtidos, mas que tem por objetivo analisar a trajetória de atletas brasileiras e suas percepções sobre a modalidade esportiva que praticam profissionalmente, segundo dimensões socioculturais, a saber: histórias pessoais, relação com família e amigos, patrocinadores e outras relações sociais. Desse modo, a questão que norteou este trabalho foi: quais as percepções de atletas de boxe olímpico feminino do Brasil sobre a modalidade que praticam profissionalmente?

Entendemos que os preconceitos e estereótipos arraigados nas sociedades contemporâneas a respeito do boxe (em geral) e da participação das mulheres (em específico) podem ser superados à medida que se conhece com maior profundidade a realidade dessas atletas segundo suas próprias narrativas.

\section{PROCEDIMENTOS METODOLÓGICOS}

No presente estudo, a abordagem metodológica envolve um processo quanti-qualitativo. Segundo Neves (1996, p. 2), "[...] os métodos quantitativos e qualitativos não se excluem. Embora difiram quanto à forma e à ênfase, trazem contribuição ao trabalho de pesquisa com procedimentos de cunho racional e intuitivo [...]". Ao longo deste tópico, pretende-se explicitar o processo desenvolvido.

A pesquisa foi realizada com atletas profissionais do boxe olímpico feminino no Brasil que foram selecionadas de maneira aleatória. Dessa forma, foram realizadas entrevistas semiestruturadas com sete atletas do boxe olímpico feminino no Brasil.

As entrevistas aconteceram no ano de 2011 durante o mês de janeiro em Salvador, Bahia, no mês de fevereiro em São Paulo e no mês de março em Brasília. No entanto, cabe destacar que as entrevistas foram previamente aplicadas, como teste-piloto, a atletas da modalidade durante o VII Campeonato Brasileiro de Boxe Feminino - do dia 25 de julho a 1 de agosto de 2010, em Aracaju, Sergipe - e durante o VII Campeonato Continental de Boxe Olímpico Feminino - de 6 a 10 de agosto de 2010, em Brasília, Distrito Federal. O projeto foi aprovado 
pelo Comitê de Ética da Universidade Católica de Brasília, cadastro 304/2010, uma vez que atendeu aos requisitos fundamentais da Resolução CNS 196/96 vigente à época.

Após as transcrições das entrevistas, combinou-se a utilização do programa Analyse Lexicale par Contexte d'un Ensemble de Segments de Texte ${ }^{3}$ (ALCESTE) para o processamento das informações quantitativas e a técnica de Análise de Conteúdo proposta por Bardin (2008), visando à categorização e análise temática das falas das atletas.

O ALCESTE, desenvolvido por Max Reinert em 1990, é um software de análise de dados textuais. "O software ALCESTE é um método de análise de conteúdo de textos que realiza uma classificação hierárquica descendente, com o objetivo de extrair os diferentes temas de um texto bem como as frases que caracterizam cada tema" (CORDEIRO, 2007, p. 59).

Com o objetivo de sintetizar e categorizar as falas das atletas realizou-se uma análise textual da produção semântica das falas, observando-se a relação entre as palavras, a frequência com que apareceram e as suas associações em classes, com o auxílio do software ALCESTE. Portanto, enquanto o software permitiu identificar a recorrência temática a partir dos vocábulos das entrevistas, o estabelecimento de categorias temáticas da análise de conteúdo permitiu "[...] a inferência de conhecimentos referentes às condições de produção / recepção (variáveis inferidas) dessas mensagens" (BARDIN, 2008, p.42). Nesse sentido, é importante enfatizar que, embora o processo de análise envolva recursos quantitativos por meio da análise estatística do ALCESTE, a ênfase da análise foi de cunho qualitativo, uma vez que o fenômeno em estudo é revestido de subjetividade, significados e sentidos interpretativos.

O ALCESTE produz uma análise estatística a partir de um arquivo de texto denominado de Unidade de Contexto Inicial (UCI) que, no caso desta pesquisa, corresponde às entrevistas transcritas. Na análise constatou-se dois grandes eixos compostos por três classes (ver Tabela 1 e Tabela 2), cada um representa um aspecto do conteúdo expresso pelas atletas. ${ }^{4}$

O primeiro eixo, "Incentivo para homens e mulheres atletas", foi constituído pelas classes 1 e 2, denominadas de "Incentivo" (classe 1) e "Diferenças de sexo e gênero" (classe 2). Esse eixo mostra as diferenças nos incetivos para mulheres e homens atletas. A expressiva frequência dos vocábulos "bolsa", "apoio", "ajuda" e "falta" (Tabela 1) evidencia a percepção das atletas em relação à falta de incentivo para elas no esporte. A Tabela 2, composta pelos vocábulos "homens", "rapaz", "mulher", "competição" entre outros, compõe a classe 2, "Diferenças de gênero".

Tabela 1 - Vocabulário do eixo 1 na Análise Hierárquica Descendente

\begin{tabular}{ccc}
\hline Classe 1 & $\mathbf{X}^{2}$ & Palavras \\
\hline & 54,31 & bols+ \\
& 48,52 & apoi+ \\
& 34,57 & ajudt+ \\
Incentivo & 30,31 & falt+ \\
& 26,87 & manter \\
& 22,99 & consegu+ \\
& 22,33 & incentivo \\
\hline
\end{tabular}

Fonte: Dados da pesquisa

3 Tradução das autoras deste artigo: Análise Lexical por Conjunto de Segmentos de um Texto.

4 As tabelas apresentadas neste tópico são ilustrativas da sistematização do software quanto à identificação dos vocábulos. Optou-se por apresentar a discussão de cada um destes eixos em categorias (como se verifica a seguir) nas quais se apresentam os resultados da análise 
Tabela 2 - Vocabulário do eixo 1 na Análise Hierárquica Descendente

\begin{tabular}{ccc}
\hline Classe 2 & $\mathbf{X}^{2}$ & Palavras \\
\hline & 58,25 & homens \\
& 41,52 & hom+ \\
& 31,61 & antiga+ \\
Diferenças de sexo e & 29,70 & competic+ \\
Gênero & 28,74 & resultado \\
& 21,50 & coquilha \\
& 23,04 & público \\
& 21,50 & rapaz \\
& 19,95 & mulher \\
\hline
\end{tabular}

Fonte: Dados da pesquisa

O segundo eixo, constituído pela classe 3 , envolve a trajetória no esporte (ver Tabela 3). Esse eixo ilustra a história das atletas nos esportes, especialmente quando iniciaram no boxe, suas percepções a respeito da modalidade e o que pretendem fazer no futuro.

A significativa frequência dos verbos "fala", "comecei", "ficava", "fiz", "mudou" e do vocábulo "academia" evidencia os relatos das atletas em relação às suas trajetórias no esporte. Analisou-se a história das atletas abordando questões como a participação nos esportes durante a infância e adolescência; os motivos que as levaram a praticar o boxe; os pontos positivos e negativos quanto a ser atleta de boxe, bem como dificuldades dessa trajetória.

Tabela 3 - Vocabulário do eixo 2 na Análise Hierárquica Descendente

\begin{tabular}{ccc}
\hline Classe 3 & $\mathbf{X}^{2}$ & Palavras \\
\hline & 16,58 & fal+ \\
& 8,50 & comec+ \\
Trajetória no & 8,02 & fic+ \\
Esporte & 7,94 & diss+ \\
& 7,93 & faz \\
& 7,45 & mud+ \\
& 7,24 & quer \\
& 6,97 & fiz \\
& 6,61 & academia
\end{tabular}

Fonte: Dados da pesquisa

$\mathrm{Na}$ apresentação das informações obtidas, a fim de preservar a identidade das atletas que participaram da investigação, as mesmas foram identificadas como A1, A2, A3, A4, A5, A6 e A7.

\section{INCENTIVO PARA HOMENS E MULHERES ATLETAS}

Segundo Hargreaves (2003), o esporte feminino foi muito negligenciado em análises da história cultural e da sociologia, tornando-se mais politizado nas décadas de 1970 e 1980. De acordo com a autora, nos anos 1970 percebeu-se, em muitos países, um aumento da participação de adolescentes e de mulheres em jogos esportivos, modificando o panorama do esporte mundial.

Para Coakley (1994), alguns fatores contribuíram para o aumento da participação desportiva de meninas e mulheres na América do Norte, tais como: as novas oportunidades de 
participação da mulher nos espaços públicos; a legislação do governo, que exigia tratamento igual para mulheres em programas públicos; o reconhecimento dos benefícios da prática de atividade física para a saúde; o fortalecimento do movimento feminista; a cobertura da mídia sobre a participação das mulheres em jogos esportivos, etc.

De acordo com Simões, Conceição e Nery (2004), durante muito tempo os homens resistiram à entrada das mulheres no cenário esportivo com o discurso de que o esporte poderia masculinizá-las, despindo-as de suas qualidades femininas. Esse processo histórico trouxe consequências à participação feminina no esporte em geral e isso se refletiu nas falas de algumas atletas entrevistadas, inclusive, quanto à falta de incentivo para a prática da modalidade.

$\mathrm{O}$ incentivo foi, de fato, um tema recorrente no discurso das atletas. Como se pode verificar nas opiniões quanto ao cenário contemporâneo sobre a participação das mulheres no boxe, as entrevistadas reiteram a falta de incentivos para a prática da modalidade tanto no que se refere a questões relacionadas a patrocínio, dinheiro, ajuda, apoio, quanto aos preconceitos.

Para aumentar a participação feminina deveria aumentar a divulgação. $O$ esporte não tem apoio. $\mathrm{O}$ grande mal do esporte é que não tem apoio. (A2)

Eu acho que mais divulgação porque não é divulgado, a gente não tem mídia em cima disso, do boxe feminino. Tudo é para outro esporte ou para o masculino, ainda o feminino a gente não tem respaldo. A gente teve uma primeira campeã mundial. Você viu ela aí? Alguém teve notícia? Alguém sabe? Ninguém. Isso é um erro... As pessoas ainda têm discriminação com o esporte. (A6)

É preciso que haja mais divulgação, que seja mais difundido e que haja mais incentivo, mais escola, mais faculdade, nas próprias academias, né? (A7)

Muita gente acha que você é marginalizada, homossexual... Existem muitos tabus. (A3)

Em suas falas, as atletas chamaram a atenção quanto à diferença de tratamento da mídia em relação ao boxe feminino. Nos últimos anos, a Lei de Incentivo ao Esporte, o Plano Decenal de Esporte e Lazer, bem como 0 apoio de estatais e empresas privadas, contribuíram para o aumento dos investimentos para o esporte de alto rendimento no Brasil. Nota-se que, apesar disso, o boxe (masculino e feminino) ainda sofre com a carência de recursos.

As informações sobre investimentos financeiros específicos para o boxe brasileiro não estão disponíveis na literatura acadêmica, nem em fontes de acesso público. Este aspecto restringe a análise do incentivo à modalidade, dado o escopo desta pesquisa. Entretanto, percebe-se que atletas e treinadores profissionais de boxe reportam a insuficiência de investimentos, sobretudo ao se manifestarem por meio da mídia. Por exemplo, ao conquistar a medalha de prata nos Jogos Olímpicos de 2012, o atleta, "Esquiva Falcão" comemorou, mas seu treinador alertou: "O boxe não tem o apoio que merece no Brasil" (GAZETA, 2012). Dessa forma, 0 boxe feminino parece sofrer as consequências de um contexto mais amplo, tal como é possível perceber nas falas das atletas A2 e A6.

\subsection{Sexo e gênero}

Ao discutirmos a fala das atletas quanto ao binômio sexo e gênero, são necessários alguns apontamentos conceituais. Neste estudo, corrobora-se Confortin (2003), que chama a atenção sobre a construção social do gênero, em outras palavras, sobre a produção do femi- 
nino e do masculino. Logo, não se trata de algo estabelecido durante o nascimento (o sexo), mas de um processo que se dá ao longo de toda a vida e faz com que as pessoas se tornem homens e mulheres de formas muito diversificadas, de acordo com as suas experiências, seus momentos históricos e sua cultura.

Não obstante, segundo Badinter (2005), ao pensar a diferença biológica como critério de classificação dos seres humanos, estaremos limitados a uma concepção binária, a uma mera relação de oposição. Goellner et al. (2009), por sua vez, apontam que a questão de gênero não é exclusiva das mulheres ou dos homens. Essas relações se estabelecem permeadas por contradições e se constroem cotidianamente nas experiências vividas que demarcam universos e olhares distintos sobre o mundo.

É possível perceber que sexo e gênero, nas narrativas das atletas entrevistadas, relacionam-se diretamente com a sexualidade. De acordo com as boxeadoras, muitas pessoas acreditam que elas sejam lésbicas por praticarem tal esporte. Seus discursos exprimem e refletem paradigmas culturais de gênero, tais como abordados por Pires e Ferraz (2008), ao indicarem que se trata de referenciais de diferenças construídas nos processos de socialização que estruturam toda a vida dos indivíduos, materializando-se em seus discursos e condutas, como se pode observar no discurso das atletas.

Eu acho que é pelo fato de ser um esporte assim masculinizado, de ser mais para homem, que é 'pancadão', tem mais contato. Então, acho que as mulheres o veem como [lugar de] se machucar. (A1)

Para fazer boxe tem que ter, assim como outro esporte também, mas boxe em especial, a menina tem que ser muito pulso firme. Porque sofre preconceito, 0 pessoal acha que é lésbica. Já que é lésbica não tem mais nenhum problema com isso (risos), tem tanto hetero quanto lésbica. (A2)

É um esporte também que todo mundo acha que é masculino. Então, existe um pouco de preconceito. Acho que ainda não tem muitas mulheres, por causa disso, mas o número tem crescido bastante. (A4)

Muita gente ainda acha que é muito violento, que vai se machucar, entendeu? Mas isso vem mudando. Cada vez mais nas competições a gente vai vendo mais meninas. É questão de mídia mesmo, de divulgar, de dizer, de esclarecer o que é realmente o esporte e que não é aquela coisa masculinizada, marginalizada. (A7).

Verificou-se nas falas das boxeadoras que muitas pessoas concebem o boxe como um esporte masculinizado, que tende a deixar quem o pratica violento e musculoso, características socialmente atribuídas aos homens. Ao mesmo tempo, as atletas destacam que houve mudanças e avanços, tais como o crescimento da prática de boxe entre as mulheres e a presença de cada vez mais mulheres atletas em competições.

Questionadas sobre a diferença das lutas de homens e mulheres, as atletas responderam não haver muita diferença. Ressaltaram haver diferença em relação à força, à velocidade, pois acreditam que os homens sejam mais fortes. As entrevistadas afirmaram que as mulheres se preocupam mais com a técnica utilizada, em fazer da luta um espetáculo bonito de se ver, enquanto os homens pensam apenas em derrubar o oponente, como se verifica a seguir.

Ah, igual a um homem, só que diminui na força, né? Só diferem dos homens na força e na velocidade. $O$ homem é mais veloz. (A1) 
Os rapazes têm mais força. Então, o impacto é maior. Então, eles sentem mais, que a pancada realmente é mais, porque a gente não tem a mesma pancada, mas no fim a gente aguenta, aguenta bastante. (A2)

Diferente é. Eu digo sempre que as mulheres são mais detalhistas. As mulheres gostam de fazer as coisas mais perfeitas, um golpe perfeito, uma coisa mais bonita. É diferente também pelas roupas. Tem meninas que se enfeitam mais, que usam sainha, as blusas são mais apertadinhas, o corpo, tal. (A4)

A diferença é mais força, só. Porque assim, se a mulher tiver a mesma força do homem não se diferencia. E as regras? Você tem que ter um protetor de seio, que hoje não é legalizado, você usa se você quer. Só que assim, a gente tem que ter uma prevenção. E homem é a coquilha. Então as regras diferem. $O$ treinamento é praticamente quase igual, porque é quatro rounds de dois minutos e o homem três rounds de três minutos. Isso para o boxe olímpico. Então o treinamento não diferencia muito não. (A6)

Hoje não tem muita diferença entre a luta de homens e mulheres. A luta feminina, em algumas competições inclusive, as lutas femininas são mais bonitas. Porque homem tem muito aquele brio de: - Ah, eu tenho que destruir, eu tenho que matar. Mulher, não, se preocupa mais com a plasticidade do movimento. (A7)

Nota-se, portanto, que os discursos das atletas sobre os aspectos relacionados às diferenças entre homens e mulheres permeiam construções sociais de gênero relacionadas ao estereótipo ("masculino" ou "feminino"), assim como diferenças comportamentais e atitudinais (em relação a como mulheres e homens atletas compreendem e se apresentam no espetáculo esportivo). Mas, ao mesmo tempo, as atletas fizeram referência indireta a fatores biologicistas (anátomo-fisiológicos), demonstrando que a percepção de gênero que engendra seus discursos engloba a dimensão biológica (sexo). De fato, uma concepção de linearidade sexo-gênero-sexualidade permeia os relatos das atletas, em sintonia com estereótipos e comportamentos que são esperados socialmente a partir da classificação biológica: o sexo.

\section{TRAJETÓRIA NO ESPORTE}

O eixo 2, composto pela classe 3, denominada "Trajetória no esporte", representa $69,17 \%$ do conteúdo das falas. Esse eixo mostra a percepção das atletas sobre a sua trajetória, bem como a de outras atletas no esporte.

Nos discursos das atletas, verificou-se que elas tiveram uma infância e adolescência ativas, com o envolvimento em outros esportes, principalmente no âmbito escolar. De acordo com Rosemberg (1995), inúmeros estudos evidenciam que a escola parece se constituir em um dos espaços privilegiados de iniciação das mulheres em Educação Física e esportes. No entanto, segundo a autora, outros estudos assinalam que, direta ou indiretamente, a escola produz e reproduz condições para a permanência de papéis sexuais tradicionais no que diz respeito ao desenvolvimento das potencialidades motoras de meninos e meninas.

No presente estudo, verificou-se que a maioria das atletas entrevistadas teve contato com outros esportes antes do boxe, sendo que, para algumas delas, esses outros esportes eram de contato ou lutas marciais. A entrada delas no boxe aconteceu entre os 16 e 19 anos. Apenas uma atleta começou a prática do boxe após os 25 anos. A passagem de prática da atividade física para competição se deu mais ou menos de três a quatro meses após o início na modalidade. 
Segundo Mennesson (2000), as lutadoras que começam o boxe após os 20 anos preferem o esporte enquanto atividade física, enquanto aquelas que começam mais cedo preferem o esporte competitivo. Os relatos abaixo ilustram a trajetória das entrevistadas.

Eu não comecei no boxe. Eu comecei no muay thai. Aí eu comecei a trabalhar e não podia treinar normalmente o muay thai. Como no boxe tinha um horário que eu podia fazer, então eu comecei a fazer o boxe. (A2)

Treinava desde meus nove anos, ginástica olímpica. Foi quando o médico me disse que não daria mais para continuar nesse esporte... Foi aí que o técnico de boxe me fez uma proposta: que eu treinasse boxe na academia só para poder manter o meu físico, não engordar. Não deu nem três meses e eu já estava apaixonada e determinada a lutar. (A3)

Foi por acaso. Eu queria fazer por estética mesmo. Aí depois eu gostei. E aí a academia que eu fui é de alto rendimento. Com três meses eu fui para o campeonato brasileiro. E aí fui campeã e me motivou bem mais. (A4)

Em sua maioria, essas atletas começaram a praticar o boxe após convites de técnicos da modalidade que, ao observá-las praticando outras atividades, propuseram a oportunidade para que elas vivenciassem o referido esporte.

A partir do início da prática do boxe, outro ponto recorrente na fala das atletas foi a questão do apoio familiar e dos amigos para a continuidade na modalidade. É possível identificar no discurso das atletas que aquelas que possuíam outra atividade profissional eram as que mais sofriam preconceitos no âmbito familiar. A avaliação das atletas sobre a relação e a percepção de suas famílias e amigos acerca do boxe é que, em geral, eles acreditavam que 0 boxe era um esporte marginalizado, agressivo, violento e discriminatório. Verificou-se que hoje a maioria dos familiares e amigos tem nova percepção a respeito do boxe e, quando podem, assistem às lutas das atletas.

Segundo Coakley (1994), as meninas não costumam receber o mesmo tipo de encorajamento que os meninos para a prática de esportes. Os meninos, em geral, são estimulados a assumirem uma postura socialmente independente, bem como a serem fisicamente ativos em atividades e em jogos esportivos. Muitas vezes, as meninas são tratadas com mais suavidade e proteção que os meninos. As meninas são assistidas mais de perto e, quando há permissão para participar de jogos esportivos ou de qualquer outra atividade, essa vem acompanhada de várias restrições, como, por exemplo: não fazer nada perigoso, não brincar com violência, não envolver-se em brigas ou discussões, etc. As falas a seguir retratam como se configura a relação das famílias das boxeadoras com o esporte.

Meu pai nunca assistiu uma luta minha. Agora, minha mãe já acompanhou algumas. Só que ela nunca assiste a luta em si. Ela vai, dá o apoio. Acho que ela tem medo, ela fica muito nervosa. (A1)

Lembro da minha primeira luta. Era minha estreia, estava com o nariz sagrando. Minha mãe não sabia que eu estava com o nariz sangrando. Escondi dela, porque eu fiquei com medo dela não deixar eu lutar. Aí ela falou que se eu tivesse falado, ela não teria mesmo deixado eu lutar não. (A2)

Antes ninguém deixou, também pelo preconceito de homem. Você vai virar homem, você vai ficar com corpo de homem, tudo assim. Mas agora está bem bacana, todo mundo me apoia, me ajuda, gosta de assistir minhas lutas. (A4) 
Minha mãe antigamente não aceitava muito não (risos). Porque, às vezes, quando eu saía da academia, eu chegava em casa com a boca partida, o rosto arranhado, lesionado e ela falava que isso era esporte de maluco, que não queria eu nele. Isso não era para mim. (A5)

Minha família não apoia o boxe, de forma nenhuma. Falam que é um esporte marginalizado, que é muito violento, que é uma perca de tempo porque não é reconhecido. Ninguém assiste nada. Nem treino. Sempre foi assim. Meus amigos falam que eu sou louca. (A7)

Consideramos que as motivações para a prática do boxe podem ser diversas, mas a permanência no esporte pode ser potencializada ou diminuída a depender do apoio e respeito de várias instâncias sociais, como a família, grupos de amigos, mídia, etc. Nesse sentido, a desmistificação dos preconceitos relacionados ao boxe deve perpassar uma ação coletiva nessas instâncias, respaldada nos equipamentos e mecanismos de segurança, destacando a história e o desenvolvimento técnico do esporte profissional.

\subsection{Percepção social em relação ao boxe feminino}

Ao relatarem sobre a visão, a percepção e os sentimentos que as outras pessoas e as mulheres da mesma idade das atletas têm sobre elas, o medo foi recorrente em seus discursos. Observa-se que ainda há visões preconceituosas em relação à participação feminina no boxe.

Segundo Lima (1993), a construção das identidades de gênero é um processo dinâmico, conduzido ao longo de uma trajetória de vida, mediante a participação na vida social segundo possibilidades que se colocam objetivamente para os sujeitos sociais. É, de fato, na experiência coletiva que cada indivíduo colhe elementos básicos e orientadores da sua autocategorização, da percepção e vivência dos papéis sexuais designados socialmente.

Para Oates (1987), o fato de ter mulher pugilista surpreende, alarma e diverte algumas pessoas uma vez que seu papel nesse desporto sempre foi marginal. 0 papel das mulheres no boxe sempre se limitou ao da mulher de cartaz ou cantora do hino nacional. Essa autora admite que o boxe foi concebido para homens e diz respeito a eles, sendo masculino. Segundo Wacquant (2002), o salão de treinamento de boxe é um espaço eminentemente masculino, no interior do qual a intromissão do gênero feminino é tolerada somente à proporção em que permanece incidental. Os relatos abaixo caracterizam as percepções das entrevistadas quanto às suas relações sociais.

Ah, pelo fato de eu ser mais fortinha e eu não falo muito com ninguém. Então, eu sou mais na minha. Mas, igual, meu irmão já chegou para mim e falou assim que elas me achavam muito feia pelo porte do corpo e tal. (A1)

As pessoas em volta da gente ficam com medo... da gente. Medo que a gente faça qualquer coisa, de bater. É engraçado: o pessoal tem medo, amigo tem medo. As pessoas comentam (risos): - Não, eu não mexeria com você. (A2)

As pessoas ficam surpreendidas comigo. Eles dizem: - Você não luta boxe, você não tem corpo de atleta de boxe, você não tem jeito de lutar boxe. Os meninos ficam meio receosos, acham que a gente é agressiva, que a gente vai brigar, vai bater. (A4)

Quem não conhece, acha que é agressivo, acha que é de homem. (A5) 
Mennesson (2000), ao realizar uma pesquisa com lutadoras de boxe, verificou que elas tiveram comportamentos diferentes na infância e na adolescência em relação a outras meninas. A autora identificou que as lutadoras eram bagunceiras, gostavam de competição, vestiam-se de forma semelhante aos meninos e preferiam a presença desses à das meninas, além de possuírem uma coordenação motora incomum para meninas. Segundo a autora, a maioria das boxeadoras afirmou ter se identificado com modelos masculinos durante a infância e, ao chegar à adolescência e fase adulta, adaptou os seus comportamentos aos padrões hegemônicos da feminilidade. As falas a seguir retratam a história de brincadeiras durante a infância das boxeadoras entrevistadas.

Eu costumo dizer que era pra eu ter nascido homem, porque (risos) eu sempre gostei de brincar de brincadeiras de homem. Nunca gostei de boneca, nunca fui de brincar de casinha, fazer comidinha, não. Eu sempre gostei de jogar bola, soltar pipa, jogar pião, brincar de biloca, sair correndo de pega ladrão (risos). (A1)

Desde pequena sempre gostei de brincadeiras de bater (risos). Eu brincava mais com meninos. (A5)

Eu gostava de boneca. Mas tinha as brincadeiras com meu irmão, tinha o salão de jogos, e eu sempre gostava de brincar com eles. Mas meu quarto era cheio de boneca. (A6)

Eu gostava de brincar de boneca, mas também brincava de pula, de esconde-esconde, brincava de carrinho. Minha família tem muitos homens, então a gente sempre fazia brincadeiras unissex para eu poder brincar. (A7)

De acordo com Saraiva (2005), é a cultura que estrutura as formas de se brincar e os objetos com que se brinca, de maneira que se pode afirmar que os brinquedos são estruturados de acordo com os sexos, principalmente a partir dos quatro ou cinco anos de idade. $\mathrm{Na}$ maioria das vezes, não é a criança quem escolhe seu brinquedo, o adulto é que impõe a ela "de que" brincar e "com o que" pode e deve brincar.

\subsection{0 futuro no esporte}

Em relação às questões sobre as expectativas futuras das atletas quando não mais puderem competir, todas responderam que gostariam de permanecer envolvidas com o boxe, seja como técnicas, árbitras, integrantes de comissão técnica, etc. Mas as atletas também relataram que financeiramente não conseguirão atuar apenas no boxe, uma vez que este ainda não é bem reconhecido e, portanto, não remunera bem.

Olha, eu vou ter que tá no meio da bagunça aqui. Alguma coisa eu vou ter que fazer. Eu tenho várias opções, ser árbitra, ser da comissão técnica. (A1)

Eu pretendo ser técnica no boxe, treinar sempre. Mas, financeiramente, não tem como, lutar, viver, financeiramente do boxe, não por muito tempo. (A2)

Eu acredito que estarei clinicando e ajudando psicologicamente vários atletas, não só do boxe, mas de outras modalidades também. (A3)

Quero ser técnica da seleção brasileira. (A6)

Sobre o fato do número de técnicos homens ser superior ao número de mulheres no boxe, as atletas comentaram que isso se deve à ausência de uma "cultura feminina" no es- 
porte, e por acreditarem que, para ser técnica, a mulher deveria primeiramente vivenciar a prática do esporte. O estudo de Oliveira (2004) parece confirmar essa perspectiva. Ao analisar histórias de sucesso de técnicas esportivas, a autora destaca a importância de verificar os fatores que influenciam ou atrapalham o acesso, a ascensão e a permanência das mulheres no comando de equipes de alto nível. Dessa forma, em sua pesquisa, identificaram-se, no discurso das informantes, as representações sociais sobre a sua trajetória no comando dessas equipes. Segundo a autora, todas são de classe média, cercadas por uma estrutura familiar que lhes deu condições de estudar e de praticar esportes desde a infância e todas se inseriram no treinamento pela sua vivência como grandes atletas. Em geral, elas declararam que, para comandar equipes de alto nível, as mulheres primeiro têm que vivenciar o esporte. Ser ex-atleta, segundo esses discursos, é pré-requisito para que elas atuem no treinamento, do contrário, não há respeito.

Ao serem questionadas sobre o porquê de apenas em 2012 o boxe feminino ter sido inserido nos Jogos Olímpicos, a maioria respondeu que a modalidade ainda sofre preconceitos, pois, segundo as boxeadoras entrevistadas, muitos veem o boxe como uma modalidade esportiva específica para homens, violenta e perigosa, conforme os relatos na sequência.

Eu acho que por falta de atleta e pelo preconceito. (A1)

Pois é, para entrar pras olimpíadas, tem que ter uma quantidade certa de países que pratiquem. Então, neste aspecto de artes marciais, de lutas, as mulheres estão vindo agora, porque os tabus estão sendo quebrados agora. Agora que a mulher está tendo ascensão. (A2)

Acho que devido ao alto rendimento feminino. O feminino vem se desenvolvendo muito bem. Está mostrando que deve estar lá. Se bem que já deveria estar lá há muito tempo, né? Também pelos resultados que estamos trazendo, não só a gente, mas também outras meninas de outros países, de outros continentes. (A4)

Eu acho que por uma mudança de visão. Uma mudança de parâmetros. Eles começaram a visualizar o boxe feminino como um esporte rentável e que tem possibilidade de crescer. (A7)

Hoje, essas meninas amadureceram tecnicamente, fisicamente. Antigamente, as meninas não eram muito técnicas. Elas estão mais detalhistas, elas estão mais amadurecidas, tanto fisicamente como tecnicamente. (A5)

As atletas relataram que está acontecendo uma mudança de visão quanto à modalidade à medida que resultados significativos vêm sendo conquistados. As falas apontam também para o aumento da participação das mulheres no boxe e para a evolução técnica das atletas. Nota-se que os resultados do boxe feminino brasileiro ao longo da história não se encontram disponíveis em fontes sistematizadas do órgão competente (a Confederação Brasileira de Boxe) e nem na produção acadêmica brasileira.

A Confederação Brasileira de Boxe foi fundada em 1933 e, desde então, passou por consecutivas reestruturações. É a partir desta instância que atletas e autoridades esportivas devem organizar sua pauta, metas e expansão. A partir dos dados deste estudo, sobretudo a partir das falas discutidas neste tópico, uma pauta que parece urgente é a sistematização e apoio para a trajetória competitiva e pós-competitiva de atletas de boxe (feminino e masculino). 


\section{CONSIDERAÇÕES FINAIS}

Ao longo do texto, foram discutidas questões relativas à participação das mulheres no boxe, diferenças de sexo e gênero e a dominação masculina no universo esportivo. Embora este trabalho apresente reflexões sobre a realidade de um grupo específico, outras interpretações podem ser feitas tendo o presente estudo como ponto de partida para discussões ampliadas em relação a outras modalidades de lutas.

Ao longo da discussão, ficou nítida a percepção das atletas de que o boxe é um esporte que tem recebido poucos incentivos financeiros. Embora todas as entrevistadas tenham bolsa-atleta, elas reportaram ter dificuldades financeiras para a prática do esporte. Para ampliar a discussão sobre o tema, pesquisas futuras devem considerar o acesso aos dados de investimentos financeiros específicos para o boxe (tanto aqueles advindos da esfera pública, como da esfera privada). Isso possibilitaria aprofundar as discussões sobre o futuro da modalidade em relação a outros esportes profissionais.

Outro aspecto que emergiu nos discursos das atletas foi a percepção de que o boxe ainda é visto, por muitas pessoas, como um esporte masculino, violento e marginalizado. Verificou-se que, em algumas famílias, o boxe passou a ser respeitado e, algumas vezes, admirado, embora ainda continue, para a maioria, uma modalidade inserida em um contexto discriminatório e marginalizado. Nesse sentido, novas análises devem considerar a percepção sobre o boxe a partir de outras instâncias sociais, como os familiares, treinadores, autoridades esportivas e os espectadores do boxe feminino.

A questão da divulgação da modalidade também foi recorrente nos discursos das atletas. Constatamos que a popularização da modalidade depende não somente dos veículos midiáticos, mas da inserção e legitimação do conteúdo "lutas" na cultura corporal, bem como das ações articuladas e contínuas do órgão que representa o boxe profissional no Brasil, a Confederação Brasileira de Boxe, para o fomento, divulgação e organização da modalidade.

Quanto às trajetórias, os discursos das atletas permitiram verificar que elas tiveram uma infância ativa e estiveram frequentemente envolvidas em brincadeiras e atividades denominadas socialmente como "masculinas"', envoltas por discriminações e preconceitos. Durante a adolescência, a maioria das atletas participou de atividades esportivas no âmbito escolar e, também, de outros tipos de lutas. Esse dado sinaliza a importância e o potencial da Educação Física para estimular a participação de crianças e jovens em atividades como as lutas. Sabe-se, porém, que este conteúdo tem sido negligenciado na Educação Física, sobretudo no âmbito escolar. Nesse sentido, urge a produção de estudos que problematizem didática e metodologicamente o ensino das lutas e as questões de gênero, dentro e fora da escola, a fim de superar os preconceitos que circundam a prática da modalidade.

Por fim, o presente estudo revela a necessidade da compreensão da prática do boxe como uma manifestação da cultura corporal que tem o potencial de oportunizar a homens e mulheres, de várias classes sociais, benefícios à saúde, bem-estar, além de uma possibilidade de carreira profissional. 


\section{REFERÊNCIAS}

BADINTER, Elisabeth. Rumo equivocado: o feminismo e alguns destinos. Tradução Vera Ribeiro. Rio de Janeiro: Civilização Brasileira, 2005.

BARDIN, Laurence. Análise de conteúdo. 5. ed. São Paulo: Edições 70, 2008.

BOYLE, Ellexis; MILLINGTON, BRAD; VERTINSKY, Patricia. Representing the female pugilist: Narratives of race, gender, and disability in Million Dollar Baby. Sociology of sport Journal, Bowling Green, v. 23, n.2, p. 99-116, 2006.

COAKLEY, Jay. Gender. Is equity the only issue? In: _.. Sport and Society: Issues and Controversies. $5^{\text {th }}$ ed. Colorado: Brown \& Benchmark, 1994. p. 326-340.

COI inclui boxe feminino na Olimpíada de 2012. ESTADÃO, São Paulo, 13 ago. 2009. Disponível em: $<$ http://www.estadao.com.br/noticias/geral,coi-inclui-boxe-feminino-na-olimpiada-de-2012,418266,0. $\underline{\mathrm{htm}}>$ Acesso em: 26 maio 2010.

COMITE OLÍMPICO INTERNACIONAL. Carta Olímpica. 2013. Disponível em: < http://www.olympic. org/documents/olympic_charter_en.pdf >. Acesso em: 12 jan. 2014.

CONFORTIN, Helena. Discurso e gênero: a mulher em foco. In: GUILARDI-LUCENA, Maria Inês (org.). Representações do Feminino. Campinas: Átomo, 2003. p. 107-123.

CORDEIRO, Yara Camargo. A relação entre a constituição de identidade e a prática da capoeira. 2007. 127 f. Dissertação (Mestrado) - Curso de Psicologia, Universidade Católica de Brasília, Brasília, 2007.

FERRETTI, Marco Antonio de Carvalho; KNIJNIK, Jorge Dorfman. Mulheres podem praticar lutas? Um estudo sobre as representações de lutadoras universitárias. Movimento, Porto Alegre, v.13, n.1, p. 57-80, 2007.

GAZETA Esportes. Técnico de Esquiva: boxe não tem o apoio que merece no Brasil. São Paulo, 2012. Disponível em: <http://gazetaonline.globo.com/_conteudo/2012/08/gazetaesportes/especiais/ olimpiadas_de_londres/noticias_-_2012/1341732-tecnico-de-esquiva--boxe-nao-tem-o-apoio-quemerece-no-brasil.html>. Acesso em: 10 jan. 2013.

GOELLNER, Silvana Vilodre et al. Mulheres e Esporte: modos de se fazer ver no skate e no fisiculturismo. In: CONGRESSO BRASILEIRO DE CIÊNCIAS DO ESPORTE, 16; CONGRESSO INTERNACIONAL DE CIÊNCIAS DO ESPORTE, 3. Anais ... Salvador: Brasil, 2009. p.1-13.

GOMES, Euza Maria de Paiva. A participação das mulheres na gestão do esporte brasileiro: desafios e perspectivas. Rio de Janeiro: Quartet/FAPERJ, 2008.

HALBERT, Christy. Tough enough and Women enough: Stereotypes, Discrimination and Impression Management among women Professional Boxers. Journal of Sports and Social Issues, Boston, v. 21, n.1, p .7-36, 1997.

HARGREAVES, Jennifer. Sporting Females: critical issues in the history and sociology of women's sports. New York: Routledge, 2003.

LIMA, Ludmila Maria Moureira."Sou o que sou porque sou diferente": Repensando o feminino e reavaliando o gênero. 1993. 192f. Dissertação (Mestrado em Sociologia)- Universidade Federal do Rio de Janeiro. Rio de Janeiro, 1993.

MACALOON, John. Olympic Games and the theory of spectacle in modern societies. In: (Ed.). Rite, drama, festival, spectacle: rehearsals toward a theory of cultural performance. Philadelphia: ISHI, 1984. p. 241-280.

MENNESSON, Christine. "Hard" woman and "soft" woman. International Review For The Sociology of Sport, London, v.35, n.1, p. 21-33, 2000. 
NEVES, José Luis. Pesquisa Qualitativa: característica, uso e possibilidades. Caderno de Pesquisas em Administração, São Paulo, v.1, n. 3, p.103-113, 1996.

OATES, Joyce Carol. 0 boxe. Tradução de Ana MacDonald de Carvalho. Rio de Janeiro: Edições 70, 1987.

OLIVEIRA, Gabriela Aragão Souza. Mulheres enfrentando o desafio da inserção, ascensão e permanência no comando de equipes esportivas de alto nível. In: SIMÕES, Antônio Carlos; KNIJNIK, Jorge Dorfman (Org.). 0 mundo psicossocial da mulher no esporte: comportamento, gênero, desempenho. São Paulo: Aleph, 2004. p.319-335.

OLIVEIRA, Gilberto; CHEREM, Eduardo Hippolyto Latsch.; TUBINO, Manoel José Gomes. A inserção histórica da mulher no esporte. Revista Brasileira de Ciência e Movimento, Brasília, v.16, n. 2, p. 117-125, 2008.

PIRES, Vera Lúcia; FERRAZ, Márcia Maria Severo. Do machismo ao masculino: o vínculo das relações de gênero transformou o homem? In: GUILARDI-LUCENA, Maria Inês; OLIVEIRA, Francisco de (orgs.). Representações do Masculino: mídia, literatura e sociedade. Campinas: Alínea, 2008. p.23-38.

ROMARIZ, Sandra Bellas; DEVIDE, Fabiano Pries; VOTRE, Sebastião. Atleta, substantivo feminino: As mulheres brasileiras nos jogos olímpicos. Movimento, Porto Alegre, v. 13, n. 1, p. 207-216, dez. 2007.

ROSEMBERG, Fúlvia. A educação física, os esportes e as mulheres: balanço da bibliografia brasileira. In: ROMERO, Elaine (Org). Corpo, mulher e sociedade. Campinas: Papirus, 1995. p. 271-308.

SARAIVA, Maria do Carmo. Co-Educação Física e esportes: quando a diferença é mito. 2. ed.. ljuí: Editora Unijuí, 2005.

SIMÕES, Antonio Carlos; CONCEIÇÃO, Paulo Felix Marcelin; NERY, Maria Aparecida da Câmara. Mulher, esporte, sexo e hipocrisia. In: SIMÕES, Antonio Carlos; KNIJNIK, Jorge Dorfman (Orgs.). 0 mundo psicossocial da mulher no esporte: comportamento, gênero, desempenho. São Paulo: Aleph, 2004. p. 61-87.

WACQUANT, Loic. Corpo e alma: notas etnográficas de um aprendiz de boxe. Tradução Angela Ramalho. Rio de Janeiro: Relume Dumará, 2002. 